\title{
A producer-retailer incorporated multi-item EPQ problem with delayed differentiation, the expedited rate for common parts, multi-delivery and scrap
}

\author{
Yuan-Shyi Peter Chiu ${ }^{a}$, Tiffany Chiu ${ }^{\text {b }}$ Fan-Yun Pai ${ }^{c^{*}}$ and Hua Yao Wu ${ }^{\text {d }}$
}

${ }^{a}$ Department of Industrial Engineering \& Management, Chaoyang University of Technology, Taiwan

${ }^{b}$ Anisfield School of Business, Ramapo College of New Jersey, Mahwah, NJ 07430, United States

${ }^{c}$ Department of Business Administration, National Changhua University of Education, Changhua County, Taiwan

${ }^{d}$ Department of Physics, College of Liberal Arts and Sciences, State Univ. of New York at Oswego, NY, United States

\section{H R O N I C L E}

Article history:

Received February 182021

Received in Revised Format

April 312021

Accepted May 12021

Available online

May, 32021

Keywords:

Producer-retailer incorporated

problem

Multi-item EPQ model

Expedited rate

Delayed differentiation

Random scrap

Multi-delivery \begin{abstract}
A B S T R A C T
Transnational producers facing the present-day competitive global supply-chain environments need to pursue the most appropriate manufacturing scheme, quality screening task, and stock shipping plan to satisfy customer's timely multi-item requirements under minimum overall product fabrication-delivery expenses. This study develops a producer-retailer incorporated multi-item two-stage economic production quantity- (EPQ-) based system with delayed differentiation, expedited-rate for common parts, multiple deliveries plan, and random scrap. It aims to assist current manufacturing firms in achieving the aforementioned operating goals. Mathematical methods help us build an analytical model to explicitly portray the studied problem's features and derive its overall system expenses. Hessian matrix equations and optimization approaches help us prove convexity and derive the cost-minimized fabricationdelivery decision. This study gives a simulated example to illustrate the research outcome's applicability and the proposed model's capabilities numerically. Consequently, diverse crucial information becomes obtainable to the manufacturers to facilitate various operating decision makings as follows: (i) the cost-minimized fabrication-delivery policy; (ii) the behavior of system's overall expenses and operating policy regarding mean scrap rate, and different relationships between common part's values and completion-rate; (iii) the system's detailed cost components; (iv) the system's overall expenses, utilization, and common part's uptime concerning different common part's expedited rates; and (v) the collective effects of critical system features on the overall expenses, uptime, and optimal cycle length, etc.
\end{abstract}

(C) 2021 by the authors; licensee Growing Science, Canada

\section{Introduction}

Meeting the increasing client's multi-item demands has urged current transnational producers to seek a more appropriate manufacturing strategy such as delayed differentiation to shorten uptime and cut down overall expenses. Gupta and Benjaafar (2004) examined the frameworks by building different models to analyze the costs and benefits of implementing delay product differentiation in various lead-time-dependent fabrication systems, including make-to-stock and make-to-order. The authors used the analytical outcomes/comparisons to obtain insights from their models. The authors also explored both the effect of selectable differentiation-point and work-sequence on lead-time-dependent fabrication systems' operating policy in terms of cost-savings. Cavusoglu et al. (2012) explored the value of information sharing and the postponement strategies and their interaction in the single- and two-level supply-chain environments. Their work, from the producer's point of view, aimed to reduce the uncertainty in demand. The authors indicated the following values from implementing the postponement: savings in stockholding cost and prevent producers from excessive and deficit in fabrication. Depending on the potential increase in

* Corresponding author

E-mail: fypai@cc.ncue.edu.tw (F.-Y. Pai)

2021 Growing Science Ltd. doi: $10.5267 /$ j.ijiec.2021.5.001 
unit cost from implementing the postponement, the interaction after combining the information-sharing strategy could be conflict, complement, or substitute with each other. On the other hand, the interaction of information sharing and the postponement strategies, from the retailer's point of view in a two-level supply-chain environment, could be beneficial or sometimes damaging. Chiu et al. (2020a) developed a postponement model to examine a multi-item replenishing policy with products' commonality, adjustable-rate on the common components, continuous stock issuing, and rework. The authors disclosed the optimal replenishing decision and the combined effect of these specific features on the postponement model's operating policy. Recent works (Mokao, 2020; Jabbarzadeh et al., 2019; Tantiwattanakul and Dumrongsiri, 2019; Lesmono et al., 2020) also studied the effect of various delayed fabrication differentiation strategies on planning, operations, and management of manufacturing/supply-chain systems.

To effectively shorten the batch cycle length, fabrication planners often consider expediting the manufacturing rate, especially when making many common intermediate components in a multi-item delayed differentiation system. Arslan et al. (2001) developed various models to investigate the correct timing and the required processes to expedite the make-to-order systems for fabricating single-product. The discrete- and continuous-time structures were examined to decide whether the outsourcing or overtime option could be more beneficial to serve as an expediting means. Ayed et al. (2011) examined a service-level constrained cost-minimized fabrication-maintenance policies incorporating variable fabricating and random demand rates. A primary machine operates with a variable fabricating rate that must meet the required service-level and demand rate but is subject to a time and fabricating-rate-dependent failure. A spare subcontracting machine will pick the production of the needed quantities. The authors first considered the effect of the features mentioned above on the problem. To reduce the facility degradation, the researchers further combined the preventive maintenance plan into their studied problem and sought optimality. Ruidas et al. (2020) examined the combined effect of variable fabricating rate, rework of defective stocks, backlogging, and demand-dependent unit selling price on a practical EPQ-based model. The authors considered (1) the fabricating rate depends on the demand rate of certain highly demandable items and (2) the multi-stage scheme for new product's fabrication. Upon developing a model with these features mentioned above, the particle swarm optimization approach helped decide the profit-maximized EPQ decision. A simulated illustration validated the applicability of their model numerically. Other studies (Aouam and Kumar, 2019; Lin et al., 2019; Jeunet and Bou Orm, 2020; Chiu et al., 2021) also explored the influence of various expedited-rate or overtime strategies on operations and management of manufacturing/supply-chain systems.

Retaining the client's desired product quality has always been one of the primary competitive strategies. Besides, in realworld supply chain environments, the producers often supply their finished goods to the customers periodically in multiple shipments. The traditional EPQ model (Taft, 1918) did not address the product-quality, nor discontinuous stock issuing matters. However, it is inevitable to encounter faulty items in most real-world manufacturing systems. Screening and removal of faulty items can make sure the finished batch's quality. Köksal et al. (2013) considered a processing center with probabilistic product-quality characteristics, rework, inspection erroring, and producer losses. The authors developed the analytical models using the Markov chain approach and the simulation techniques for the problem. They concluded that improving process capability is the most beneficial way to eliminate inspection errors and potential losses. Rout et al. (2020) studied an EPQ model featuring deteriorating stocks, imperfect fabrication, backlogging, rework, and inspection errors. The authors examined both Type one and Type two inspection errors and analyzed their consequent rework and sales return. The researchers aimed at simultaneously deciding the most economic batch-backlogging sizes that kept the total system expenses at a minimum. Recent works (Pramono et al., 2018; Marchi et al., 2019; Ortiz-Servin et al., 2019; Palyanitsina and Sukhikh, 2020; Gera, 2021) investigated the impact of faulty goods on planning, controlling, and management of manufacturing systems. As stated earlier, in most real-world supply-chain environments, the transnational producers frequently employ the multi-delivery policy in transporting their goods to customers. Farsijani et al. (2012) considered a multiproduct EPQ-based model with the following deterministic characteristics: the imperfect process, rework, limited space, backlogging, and discrete shipping orders. The authors proposed a simulated annealing method to resolve this non-linear oriented integer problem and presented examples to show their model's applicability numerically. Pawar and Nandurkar (2018) jointly decided the operating policies for a single-vendor multi-buyer multiproduct supply-chain system. These policies include (i) each customer's reordering point for each product and (ii) each product's optimal shipping quantities. The aim was to keep the overall system-relevant cost at a minimum. Their model considered backlogging and lost sales for the allowable shortages. The researchers applied various optimization methods/algorithms for solving the problem. Other recent works (Larkin and Privalov, 2019; López-Ruíz and Carmona-Benítez, 2019; Tian and Guo, 2019; Gilotra et al., 2020; Kauppila et al., 2020; Trisna et al., 2020) explored the impact of various aspects of shipping strategies on the planning and management of specific supply chain systems. As few past works focused on the collective effect of delayed differentiation, the expedited-rate, multidelivery, and random scrap on the producer-retailer incorporated multi-item EPQ problem, we intend to fill this gap.

\section{The proposed multi-item EPQ problem}

\subsection{Description and formulations}

This study examines a producer-retailer incorporated multi-item economic production quantity (EPQ) problem with delayed differentiation, the expedited rate for common parts, multi-delivery, and scrap. Planning a multi-item batch production with 
a common intermediate component, managers often evaluate a delayed differentiation scheme aiming to expedite the completion time and/or cut down the overall cost. Likewise, this study considers a two-stage delayed differentiation scheme to explore this particular producer-retailer incorporated multi-item EPQ problem. Stage one applies an expedited rate to fabricate the common intermediate components, and stage two uses a regular rate to make the retailer's order of $L$ distinct finished products.

A constant completion ratio $\gamma$ of the common intermediate part is assumed. Stage one's expedited rate $P_{\mathrm{T} 1,0}$ (as shown in Eq. (1)) increases regular rate $P_{1,0}$ by $\alpha_{1,0}$ proportion to reduce stage one's uptime.

$$
P_{\mathrm{T} 1,0}=P_{1,0}\left(1+\alpha_{1,0}\right)
$$

The following formulas further explain its consequent cost-increase relationship:

$$
\begin{aligned}
& K_{\mathrm{T} 0}=\left(1+\alpha_{2,0}\right) K_{0} \\
& C_{\mathrm{T} 0}=\left(1+\alpha_{3,0}\right) C_{0}
\end{aligned}
$$

where $K_{\mathrm{T} 0}, K_{0}, C_{\mathrm{T} 0}, C_{0}, \alpha_{2,0}$, and $\alpha_{3,0}$ represent the special and regular setup and unit costs, and connected factors between cost variables due to implementing expedited-rate. The following defines additional notation in this study:

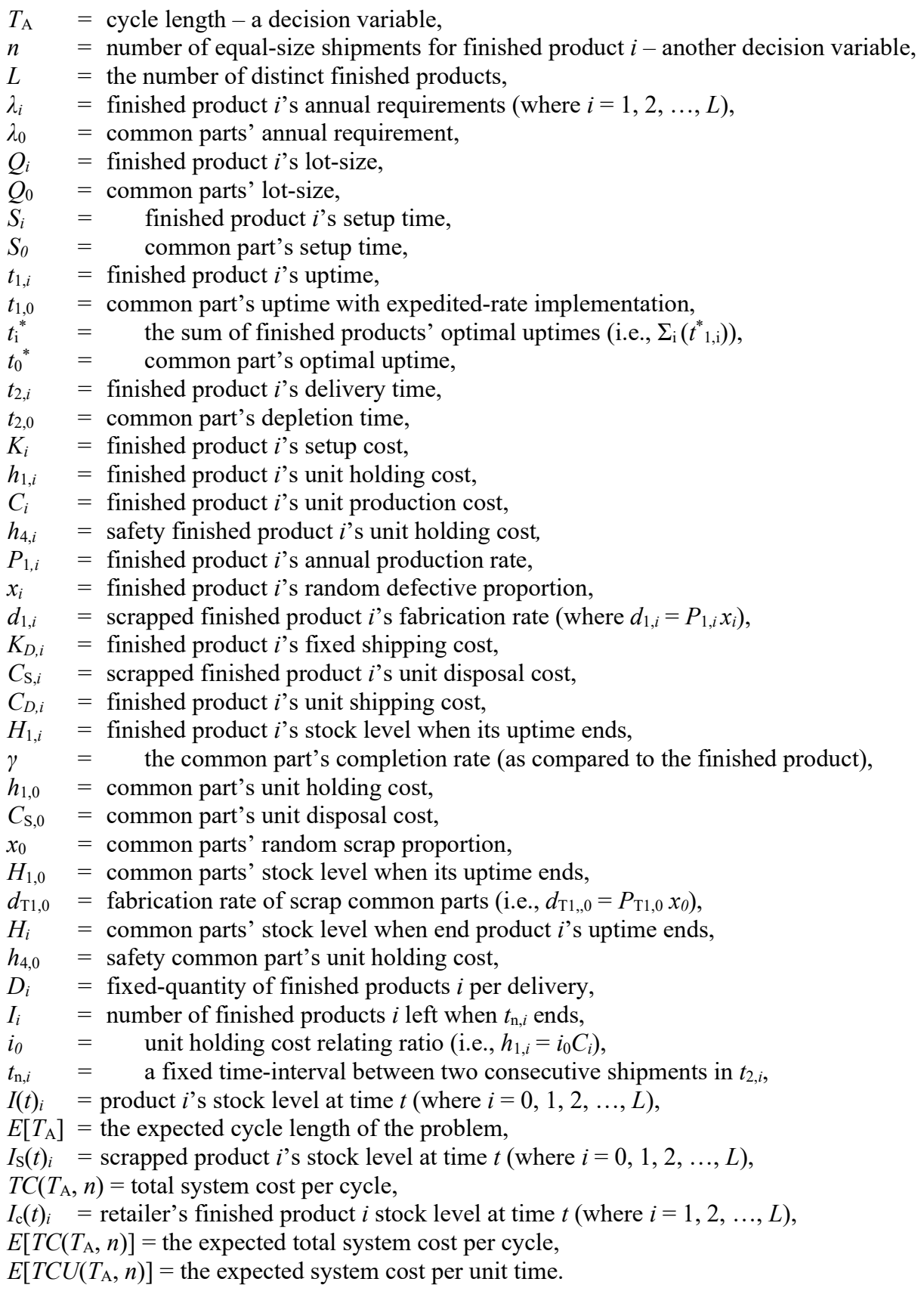


Fig. 1 illustrates the proposed model's perfect stock level. It shows that when stage one's uptime ends, the perfect stock level increases to $H_{1,0}$ before the $2^{\text {nd }}$ stage begins. As the fabrication of finished product $i$ initiates, the common intermediate parts gradually deplete. Stock level of each end product $i$ surges to $H_{1, i}$ when its uptime completes. Due to no stock-out condition permitted, both $\left(P_{\mathrm{T} 1,0}-d_{\mathrm{T} 1,0}-\lambda_{0}\right)$ and $\left(P_{1, i}-d_{1, i}-\lambda_{i}\right)$ must $>0$. Furthermore, this study assumes scrap proportions $x_{0}$ and $x_{i}$ associated with each fabricating stage, and the scrap items' fabrication rates respectively are $d_{\mathrm{T} 1,0}$ and $d_{1, i}$. Figure 2 depicts the studied problem's scrap stock level in both stages. It shows that the scrap stock surges to $\left(d_{\mathrm{T} 1,0} t_{1,0}\right)$ and $\left(d_{1, i} t_{1, i}\right)$ respectively when uptimes end. These scraps are screened and discarded at a unit disposal cost of $C_{\mathrm{S}, 0}$, and $C_{\mathrm{S}, i}$, respectively. The following expressions are gained according to our stage two's assumption (where $i=1,2, \ldots, L$ ):

$$
\begin{aligned}
& Q_{i}=\frac{\lambda_{i} T_{\mathrm{A}}}{1-x_{i}} \\
& T_{\mathrm{A}}=\frac{Q_{i}\left(1-x_{i}\right)}{\lambda_{i}}=t_{1, i}+t_{2, i} \\
& d_{1, i}=P_{1, i} x_{i} \\
& t_{2, i}=T_{\mathrm{A}}-t_{1, i} \\
& H_{1, i}=t_{1, i}\left(P_{1, i}-d_{1, i}\right) \\
& t_{1, i}=\frac{Q_{i}}{P_{1, i}}=\frac{H_{1, i}}{P_{1, i}-d_{1, i}}
\end{aligned}
$$

Stage one's required common intermediate parts to fulfill end products' fabrication are exhibited in Eq. (10) (refer to Eq. (4)), and more expressions are observed according to stage one's assumption as follows:

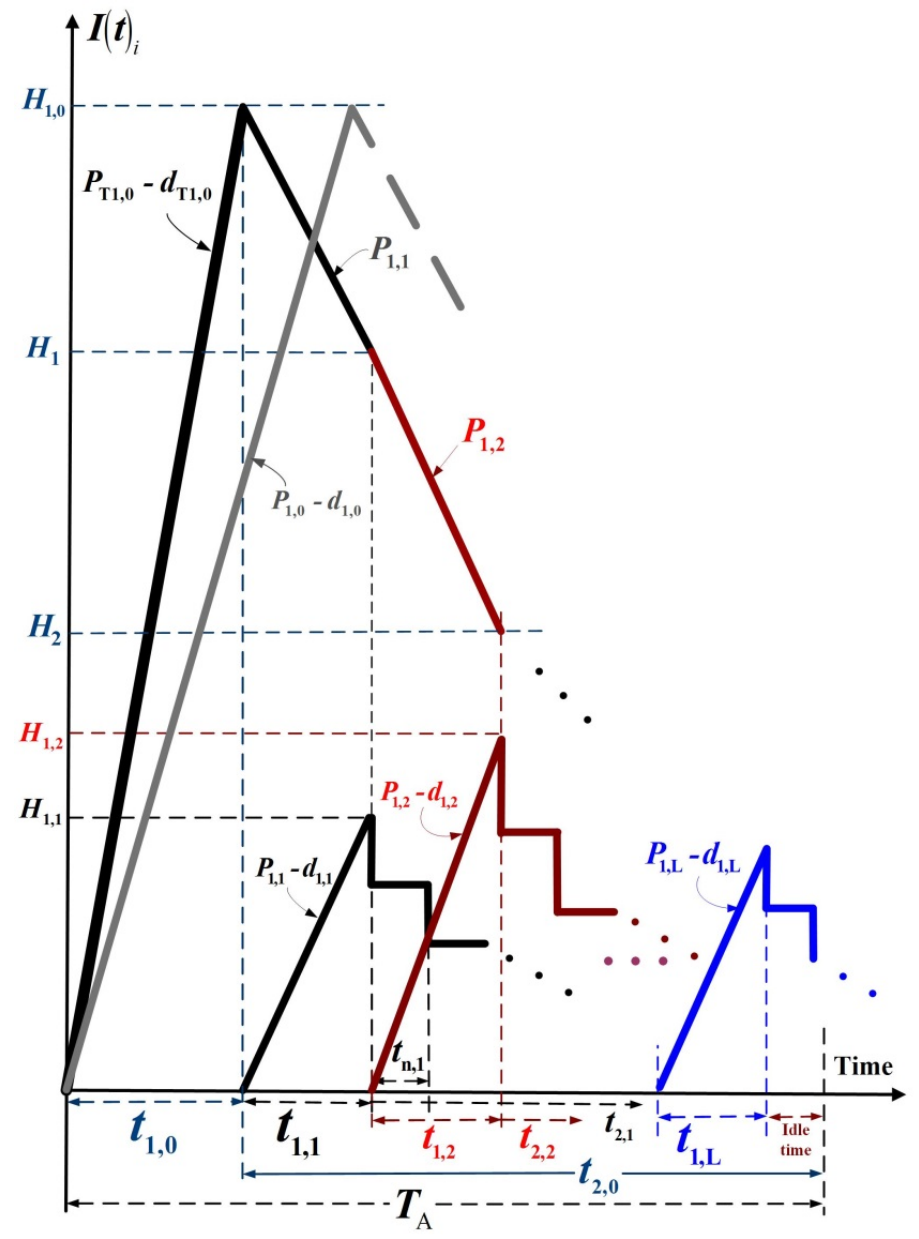

Fig. 1. Level of perfect stock of the present multi-item delayed differentiation EPQ problem with multi-delivery, expedited rate, and scrap compared to the same problem without expedited rate (in grey) 


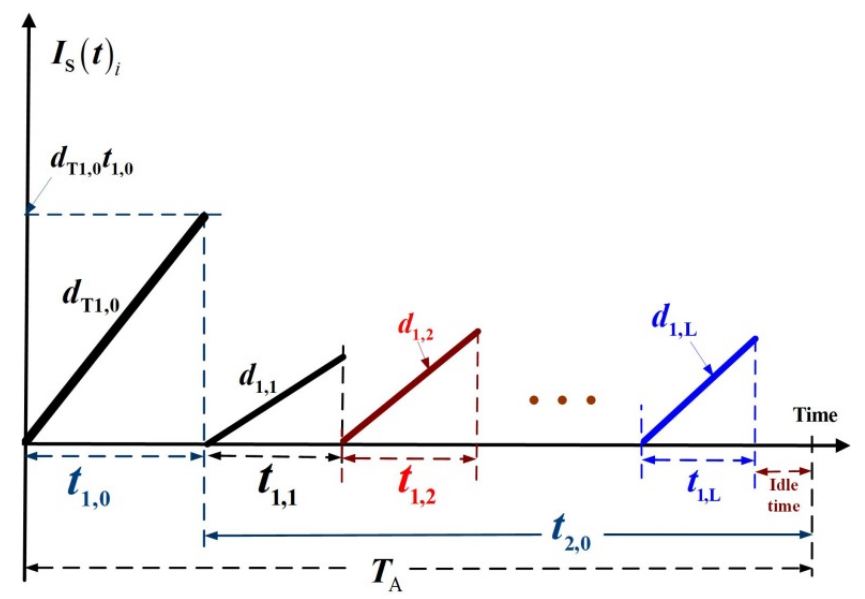

Fig. 2. Level of scrap stock in the studied problem

$H_{1,0}=\sum_{i=1}^{L} Q_{i}=\sum_{i=1}^{L} \frac{\lambda_{i} T_{\mathrm{A}}}{1-x_{i}}$

$Q_{0}=\frac{H_{1,0}}{1-x_{0}}$

$\lambda_{0}=\frac{\sum_{i=1}^{L} Q_{i}}{T_{\mathrm{A}}}$

$T_{\mathrm{A}}=t_{1,0}+t_{2,0}$

$t_{1,0}=\frac{Q_{0}}{P_{T 1,0}}=\frac{H_{1,0}}{P_{T 1,0}-d_{T 1,0}}$

$d_{T 1,0}=P_{T 1,0} x_{0}$

$H_{1,0}=\left(P_{T 1,0}-d_{T 1,0}\right) t_{1,0}$

$H_{1}=H_{1,0}-Q_{1}$

$H_{i}=H_{(i-1)}-Q_{i}$, for $i=2,3, \ldots, L$

$H_{L}=H_{(L-1)}-Q_{L}=0$

Fig. 3 exhibits the producer's finished stock level in delivery time. The maximum stock level $H_{1, i}$ are transported to retailer under $n$ equal-size shipments in every $t_{n, i}$ period and the total inventories in $t_{2, i}$ is expressed in Eq. (20) (Chiu et al., 2019):

$$
\left(\frac{1}{n^{2}}\right)\left(\sum_{i=1}^{n-1} i\right) H_{1, i}\left(t_{2, i}\right)=\left(\frac{1}{n^{2}}\right)\left[\frac{n(n-1)}{2}\right] H_{1, i}\left(t_{2, i}\right)=\left(\frac{n-1}{2 n}\right) H_{1, i}\left(t_{2, i}\right)
$$

At the retailer side, each product $i$ 's stock level are displayed in Figure 4, and the retailer's total inventories are expressed in Eq. (21) (Chiu et al. (2020b)):

$$
\left[\frac{n\left(D_{i}-I_{i}\right) t_{n, i}}{2}+\frac{n(n+1)}{2} I_{i} t_{n, i}+\frac{n I_{i}\left(t_{1, i}\right)}{2}\right]
$$

where

$$
\begin{aligned}
& I_{i}=D_{i}-\lambda_{i}\left(t_{n, i}\right) \\
& t_{n, i}=\frac{t_{2, i}}{n}
\end{aligned}
$$




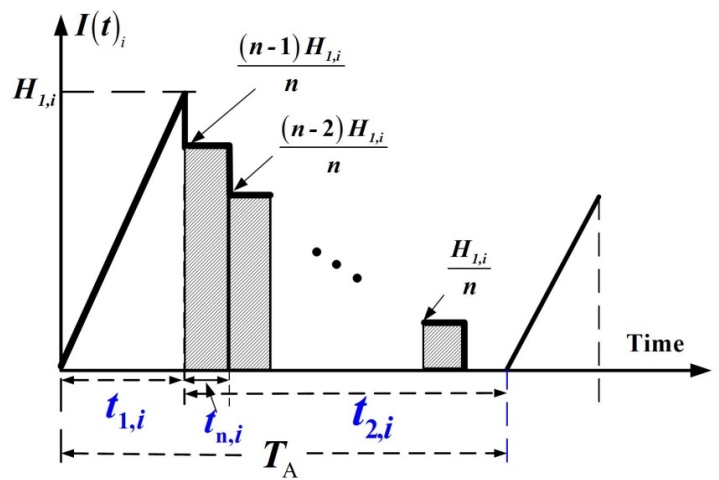

Fig. 3. Level of producer's finished product $i$ in $t_{2, i}$

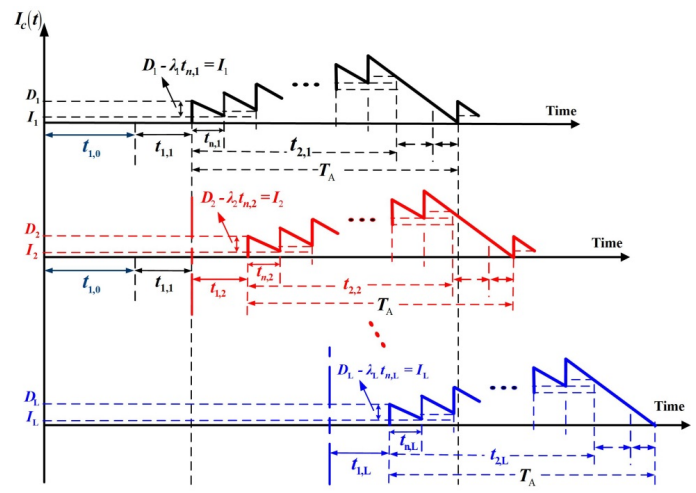

Fig. 4. Level of retailer's stock of each product $i$

\section{Total system cost and the optimal replenishment-shipment policy}

\subsection{Total cost function}

Total system cost function per cycle $T C\left(T_{\mathrm{A}}, n\right)$ comprises the following fabrication-shipment relevant costs: (1) variable, (2) setup, (3) disposal, (4) finished items' shipping, and (5) holding at both producer and retailer sides:

$$
\begin{aligned}
T C\left(T_{A}, n\right)= & \left\{C_{T 0} Q_{0}+K_{T 0}+h_{4,0}\left(x_{0} Q_{0}\right) T_{A}+C_{S, 0}\left(Q_{0} x_{0}\right)+h_{1,0}\left[\frac{H_{1,0} t_{1,0}}{2}+\frac{d_{T 1,0} t_{1,0}}{2}\left(t_{1,0}\right)+\sum_{i=1}^{L}\left[\frac{Q_{i}}{2}\left(t_{1, i}\right)+H_{i}\left(t_{1, i}\right)\right]\right]\right\} \\
& +\sum_{i=1}^{L}\left\{\begin{array}{l}
C_{i} Q_{i}+K_{i}+C_{S, i}\left(Q_{i} x_{i}\right)+n K_{D, i}+C_{D, i} Q_{i}\left(1-x_{i}\right)+h_{1, i}\left[\frac{H_{1, i} t_{1, i}}{2}+\left(\frac{n-1}{2 n}\right) H_{1, i}\left(t_{2, i}\right)+\frac{d_{1, i} t_{1, i}}{2}\left(t_{1, i}\right)\right] \\
+h_{4, i}\left(x_{i} Q_{i}\right) T_{A}+h_{3, i}\left[\frac{n\left(D_{i}-I_{i}\right) t_{n, i}}{2}+\frac{n(n+1)}{2} I_{i} t_{n, i}+\frac{n I_{i}\left(t_{1, i}\right)}{2}\right]
\end{array}\right\}
\end{aligned}
$$

With further derivation, $\left.E\left[T C U\left(T_{\mathrm{A}}, n\right)\right)\right]$ is gained as follows (see Appendix A):

$$
\begin{aligned}
E[ & \left.T C U\left(T_{A}, n\right)\right]=\left(1+\alpha_{3,0}\right) C_{0} \lambda_{0} E_{00}+\frac{\left(1+\alpha_{2,0}\right) K_{0}}{T_{A}} \\
& +C_{S, 0} E_{10} \lambda_{0}+h_{4,0} \lambda_{0} E_{10} T_{A}+h_{1,0} \sum_{i=1}^{L}\left(\frac{1}{2 P_{1, i}}\right) \lambda_{i}^{2}\left(E_{0 i}\right)^{2} T_{A} \\
& +h_{1,0}\left\{\begin{array}{l}
\left.\left(\frac{1}{2}\right) \lambda_{0}^{2}\left(E_{00}\right)^{2} T_{A} E_{0 P}+\sum_{i=1}^{L}\left(\frac{-\lambda_{i} E_{0 i} T_{A}}{P_{1, i}}\right)\left[\sum_{j=1}^{i}\left(\lambda_{j} E_{0 j}\right)\right]+\left[\sum_{i=1}^{L}\left(\lambda_{i} E_{0 i}\right)\right] \cdot \sum_{i=1}^{L}\left(\frac{\lambda_{i} E_{0 i} T_{A}}{P_{1, i}}\right)\right\} \\
+
\end{array}\right. \\
& +\sum_{i=1}^{L}\left\{\begin{array}{l}
C_{i} \lambda_{i} E_{0 i}+\frac{K_{i}}{T_{A}}+C_{S, i}\left(\lambda_{i} E_{1 i}\right)+\frac{n K_{D, i}}{T_{A}}+C_{D, i} \lambda_{i}+\frac{h_{1, i} \lambda_{i}^{2} T_{A} E_{2 i}}{2}+h_{4, i} \lambda_{i} E_{1 i} T_{A} \\
+\frac{h_{3, i}}{2}\left(\frac{E_{0 i}}{P_{1, i}}\right)^{2} \lambda_{i}^{2} T_{A}+\frac{\left(h_{3, i}-h_{1, i}\right) \lambda_{i}^{2} T_{A} E_{i P}}{2 n}
\end{array}\right\}
\end{aligned}
$$

\subsection{The optimal replenishment-shipment policy}

The Hessian Matrix Equations are applied to $E\left[T C U\left(T_{\mathrm{A}}, n\right)\right]$ (Rardin (1998)) to gain the result as follows:

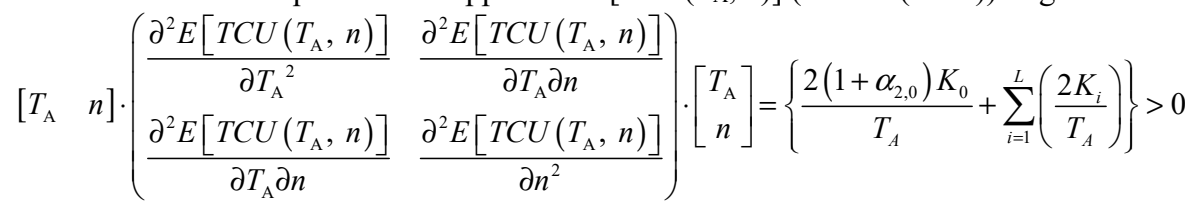

The result in Eq. (37) yields positive, for $T_{\mathrm{A}},\left(1+\alpha_{2,0}\right), K_{i}$, and $K_{0}$ are positive. Therefore, $E\left[T C U\left(T_{\mathrm{A}}, n\right)\right]$ is proved to be strictly convex for all $n$ and $T_{\mathrm{A}}$ other than zero. It follows that by solving the linear system of the following first-derivatives of $E\left[T C U\left(T_{\mathrm{A}}, n\right)\right]$ relating to $n$ and $T_{\mathrm{A}}$, the optimal $T_{\mathrm{A}} *$ and $n *$ can be determined simultaneously:

$$
\frac{\partial E\left[T C U\left(T_{\mathrm{A}}, n\right)\right]}{\partial n}=\sum_{i=1}^{L}\left[\frac{K_{D, i}}{T_{A}}-\frac{\left(h_{3, i}-h_{1, i}\right)}{2 n^{2}}\left(\lambda_{i}^{2} T_{A} E_{i P}\right)\right]=0
$$




$$
\frac{\partial E\left[T C U\left(T_{\mathrm{A}}, n\right)\right]}{\partial T_{\mathrm{A}}}=\left\{\begin{array}{l}
\frac{-\left(1+\alpha_{2,0}\right) K_{0}}{T_{A}^{2}}+h_{4,0} E_{10} \lambda_{0}+h_{1,0} \sum_{i=1}^{L}\left(\frac{\lambda_{i}^{2}}{2 P_{1, i}}\right)\left(E_{0 i}\right)^{2}+\sum_{i=1}^{L}\left\{\frac{-\left(K_{i}+n K_{D, i}\right)}{T_{A}^{2}}\right\}+ \\
h_{1,0}\left\{\left(\frac{\lambda_{0}{ }^{2} E_{0 P} E_{00}{ }^{2}}{2}\right)-\sum_{i=1}^{L}\left(\frac{\lambda_{i} E_{0 i}}{P_{1, i}}\right)\left[\sum_{j=1}^{i}\left(\lambda_{j} E_{0 j}\right)\right]+\left[\sum_{i=1}^{L}\left(\lambda_{i} E_{0 i}\right)\right] \sum_{i=1}^{L}\left(\frac{\lambda_{i} E_{0 i}}{P_{1, i}}\right)\right\} \\
+\sum_{i=1}^{L}\left\{\frac{h_{1, i} \lambda_{i}^{2} E_{2 i}}{2}+h_{4, i} \lambda_{i} E_{1 i}+\frac{h_{3, i}}{2}\left(\frac{\lambda_{i}^{2}}{P_{1, i}}\right) E_{0 i}+\frac{\left(h_{3, i}-h_{1, i}\right) \lambda_{i}^{2} E_{i P}}{2 n}\right\}
\end{array}\right\}=0
$$

Therefore, we find the following optimal replenishment-delivery policy $\left(T_{\mathrm{A}} *, n^{*}\right)$ :

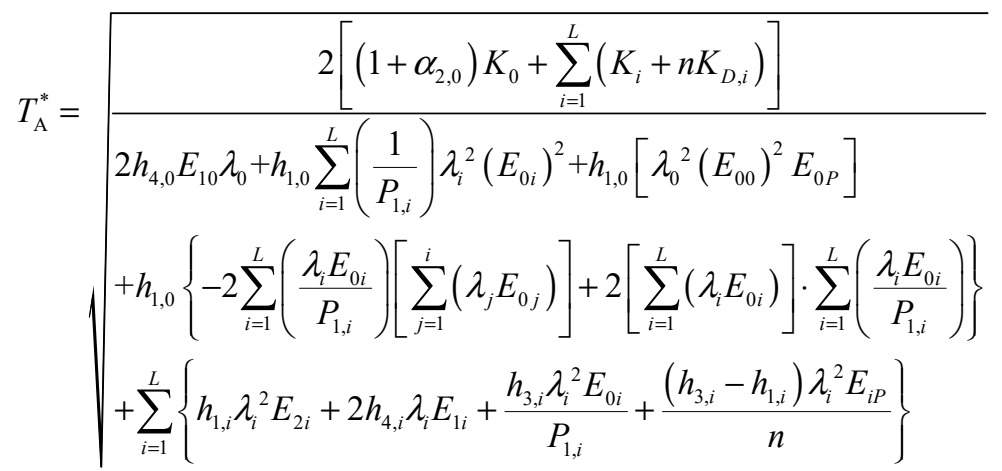

and

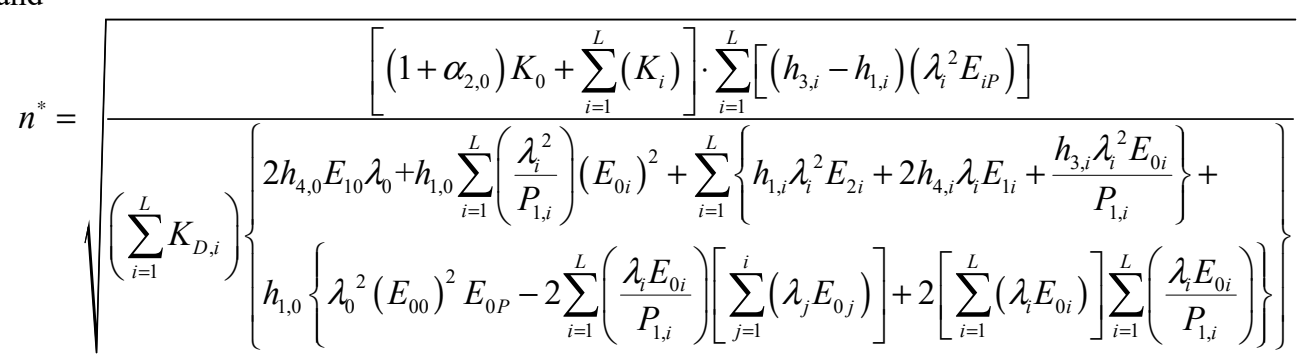

\subsection{Discussion of the setup times}

The sum of setup times $S_{\mathrm{i}}$ may be insignificant to the cycle length. However, to ensure they won't affect our replenishment cycle, one could compute the following $T_{\min }$ (Nahmias (2009)) and verify that $T_{\min }<T_{\mathrm{A}}{ }^{*}$. If not, choose the maximum of $\left(T_{\min }, T_{\mathrm{A}} *\right)$ as the feasible operating cycle.

$$
T_{\min }=\frac{\sum_{i=0}^{L} S_{i}}{1-\left\{\frac{\lambda_{0}}{\left[1-E\left[x_{0}\right]\right]}\left(\frac{1}{P_{T 1,0}}\right)+\sum_{i=1}^{L} \frac{\lambda_{i}}{\left[1-E\left[x_{i}\right]\right]}\left(\frac{1}{P_{1, i}}\right)\right\}}
$$

\subsection{Capacity constraints}

Furthermore, the machine must have adequate capacity to produce the common intermediate components and finished multiproduct in this two-stage postponement EPQ problem. That is, Eqs. (33) and (34) must hold (Nahmias, 2009):

$$
\left[\left(t_{1,0}\right)+\sum_{i=1}^{L}\left(t_{1, i}\right)\right]<T_{\mathrm{A}} \text { or }\left[\left(\frac{Q_{0}}{P_{T 1,0}}\right)+\sum_{i=1}^{L}\left(\frac{Q_{i}}{P_{1, i}}\right)\right]<T_{\mathrm{A}}
$$

or

$$
\left[\frac{\lambda_{0}}{\left[1-E\left[x_{0}\right]\right]}\left(\frac{1}{P_{T 1,0}}\right)+\sum_{i=1}^{L} \frac{\lambda_{i}}{\left[1-E\left[x_{i}\right]\right]}\left(\frac{1}{P_{1, i}}\right)\right]<1
$$

\section{Numerical example}

The following simulated example helps demonstrate the applicability/capability of this specific producer-retailer incorporated multi-item EPQ problem with delayed differentiation, expedited- rate, multi-delivery, and scrap. A two-stage batch manufacturing plan must meet five end items with the following assumed parameters' values in each stage: 
Table 1

Stage one's assumed parameters' values

\begin{tabular}{cccccccccccccc}
\hline$\gamma$ & $x_{0}$ & $\delta$ & $C_{0}$ & $P_{1,0}$ & $K_{0}$ & $h_{1,0}$ & $C_{\mathrm{S}, 0}$ & $\cdot \lambda_{0}$ & $\alpha_{1,0}$ & $\mathrm{i}_{0}$ & $\alpha_{2,0}$ & $h_{4,0}$ & $\alpha_{3,0}$ \\
\hline 0.5 & $2.5 \%$ & 0.5 & $\$ 40$ & 120000 & $\$ 8500$ & $\$ 8$ & $\$ 10$ & 18218 & 0.5 & 0.2 & 0.1 & $\$ 8$ & 0.25 \\
\hline
\end{tabular}

Table 2

Stage two's assumed parameters' values

\begin{tabular}{|c|c|c|c|c|c|c|c|c|c|c|c|}
\hline Product $i$ & $\overline{C_{i}}$ & $x_{i}$ & $K_{D, i}$ & $C_{\mathrm{S}, i}$ & $C_{\mathrm{D}, i}$ & $h_{1, i}$ & $P_{1, i}$ & $h_{4, i}$ & $\lambda_{i}$ & $h_{3, i}$ & $K_{i}$ \\
\hline 1 & $\$ 40$ & $2.5 \%$ & $\$ 1800$ & $\$ 10$ & $\$ 0.1$ & $\$ 16$ & 112258 & $\$ 16$ & 3000 & $\$ 70$ & $\$ 8500$ \\
\hline 2 & $\$ 50$ & $7.5 \%$ & $\$ 1900$ & $\$ 15$ & $\$ 0.2$ & $\$ 18$ & 116066 & $\$ 18$ & 3200 & $\$ 75$ & $\$ 9000$ \\
\hline 3 & $\$ 60$ & $12.5 \%$ & $\$ 2000$ & $\$ 20$ & $\$ 0.3$ & $\$ 20$ & 120000 & $\$ 20$ & 3400 & $\$ 80$ & $\$ 9500$ \\
\hline 4 & $\$ 70$ & $17.5 \%$ & $\$ 2100$ & $\$ 25$ & $\$ 0.4$ & $\$ 22$ & 124068 & $\$ 22$ & 3600 & $\$ 85$ & $\$ 10000$ \\
\hline 5 & $\$ 80$ & $22.5 \%$ & $\$ 2200$ & $\$ 30$ & $\$ 0.5$ & $\$ 24$ & 128276 & $\$ 24$ & 3800 & $\$ 90$ & $\$ 10500$ \\
\hline
\end{tabular}

In comparison, the assumed parameters' values for the corresponding single-stage system are listed in Table B-1 (Appendix B).

\subsection{The optimal operating replenishing-delivery policy}

Apply Eqs. (30), (31), and (26) to obtain $T_{\mathrm{A}}^{*}=0.4623, n^{*}=3$, and $E\left[T C U\left(T_{\mathrm{A}}^{*}, n^{*}\right)\right]=\$ 2,459,701$. Figure 5 shows the behavior of $E\left[T C U\left(T_{\mathrm{A}}, n\right)\right]$ concerning $T_{\mathrm{A}}$ and $n$. $E\left[T C U\left(T_{\mathrm{A}}, n\right)\right]$ knowingly surges as $T_{\mathrm{A}}$ and $n$ deviates from their optimal values.

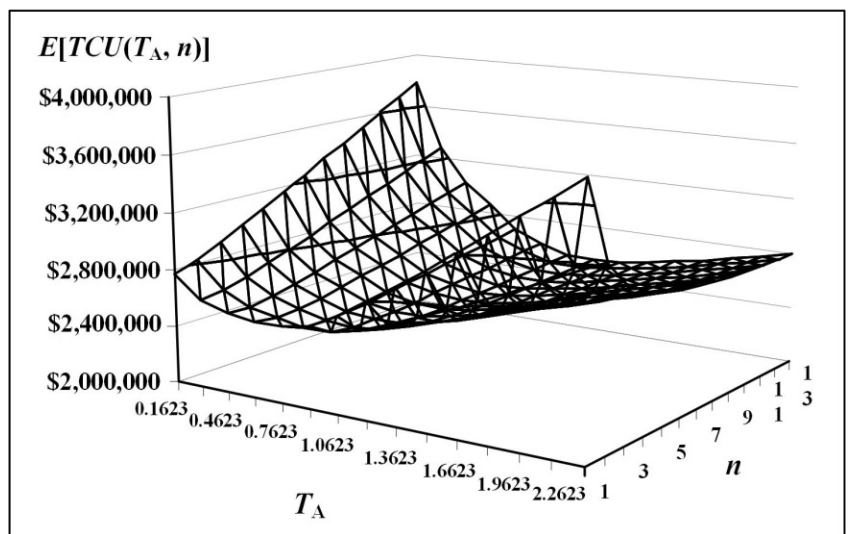

Fig. 5. The convexity of $E\left[T C U\left(T_{\mathrm{A}}, n\right)\right]$ concerning $T_{\mathrm{A}}$ and $n$

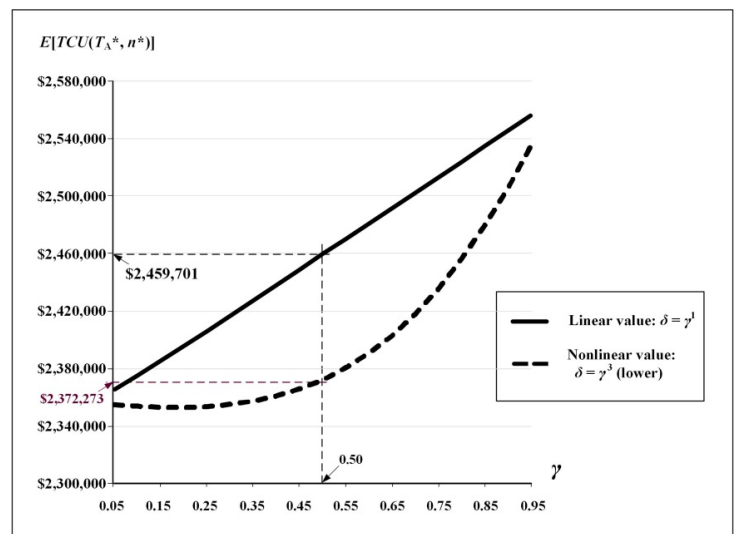

Fig. 6. The behavior $E\left[T C U\left(T_{\mathrm{A}}^{*}, n^{*}\right)\right]$ regarding linear and nonlinear relationships of $\delta$ and $\gamma$

\subsection{The critical system features effect on the problem}

Fig. 6 explores the behavior of $E\left[T C U\left(T_{\mathrm{A}}^{*}, n^{*}\right)\right]$ concerning the nonlinear and linear relationships of common part's values $\delta$ and its completion rate $\gamma$. For $\gamma=0.5$ in the linear case (i.e., our assumption: $\left.\delta=\gamma^{1}\right)$, it reconfirms $E\left[T C U\left(T_{\mathrm{A}}^{*}, n^{*}\right)\right]=$ $\$ 2,459,701$. The nonlinear case with lower component value (i.e., $\left.\delta=\gamma^{3}\right)$, for $\gamma=0.5, E\left[T C U\left(T_{\mathrm{A}}^{*}, n^{*}\right)\right]=\$ 2,372,273$. Fig. 7 investigates the behavior of TA* relating to the linear and nonlinear relationships of $\delta$ and $\gamma$. For $\gamma=0.5$ in the linear case, it reconfirms $\mathrm{TA}^{*}=0.4623$. The nonlinear case with lower component value, for $\gamma=0.5$, TA $=0.5871$.

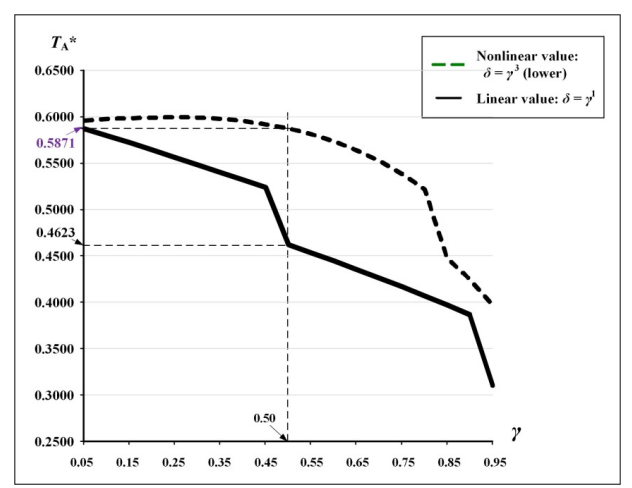

Fig. 7. The behavior $T_{\mathrm{A}}$ * regarding the linear and nonlinear relationships of $\delta$ and $\gamma$

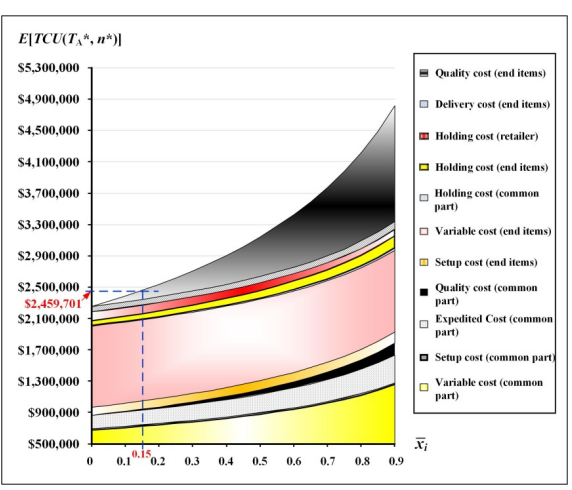

Fig. 8. The mean scrap rate $x_{i}$ effect on different cost contributors of $E\left[T C U\left(T_{\mathrm{A}}^{*}, n^{*}\right)\right]$ 
The mean scrap rate $x_{i}$ effect on different cost contributors of $E\left[T C U\left(T_{\mathrm{A}}{ }^{*}, n^{*}\right)\right]$ is exhibited in Figure 8. At mean $x_{i}=0.15$, it confirms $E\left[T C U\left(T_{\mathrm{A}}^{*}, n^{*}\right)\right]=\$ 2,459,701$ (i.e., the optimal solution of our example). The end items' quality cost has the most impact when mean $x_{i}$ rises. The common components' variable, setup, and quality relevant costs also knowingly surge as the mean $x_{i}$ increases. Fig. 9 analyzes the detailed cost contributors of $E\left[T C U\left(T_{\mathrm{A}}^{*}, n^{*}\right)\right]$. Two main cost contributors are variable costs for end products and common parts; each takes $42.28 \%$ and $29.53 \%$. The common parts' expediting expense of $7.58 \%$ is the third-largest contributor. The fourth-largest contributor is the overall (both stages) quality relevant costs of $5.19 \%$. It follows that the retailer's holding and setup cost $4.55 \%$ and $4.18 \%$. Then, the end products' delivery cost $2.85 \%$.

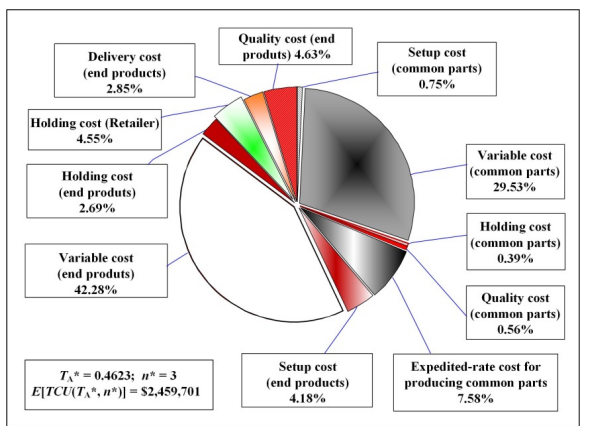

Fig. 9. The detailed cost contributors of $E\left[T C U\left(T_{\mathrm{A}} * n^{*}\right)\right]$

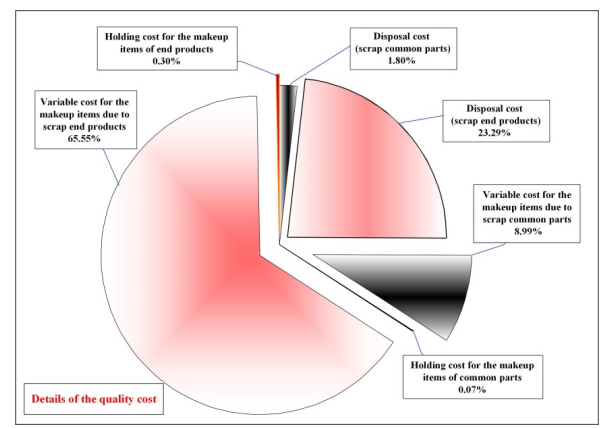

Fig. 10. The detailed cost contributors to system quality cost in $E\left[T C U\left(T_{\mathrm{A}}^{*}, n^{*}\right)\right]$

The analytical outcomes of overall quality relevant costs are exhibited in Figure 10. It indicates the variable cost for the makeup end items (due to scrap end products) contributes $65.55 \%$, the most in quality cost. The disposal cost for scrap end products contributes $23.29 \%$, the second-largest quality cost. It follows that the variable cost for the makeup common parts of $8.99 \%$ is the third-largest quality cost component. Fig. 11 depicts the expedited ratio $\left(P_{\mathrm{T} 1,0} / P_{1,0}\right)$ effect on the optimal uptime $t_{0} *$. At $\left(P_{\mathrm{T} 1,0} / P_{1,0}\right)=1.5$, stage one's optimal uptime $t_{0} *$ declines to 0.0474 (years) from 0.0704 , a $32.67 \%$ drop.

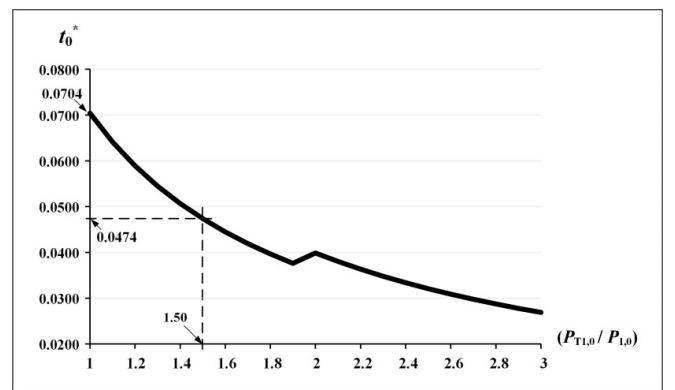

Fig. 11. The expedited ratio $\left(P_{\mathrm{T} 1,0} / P_{1,0}\right)$ effect on the optimal uptime $t_{0} *$

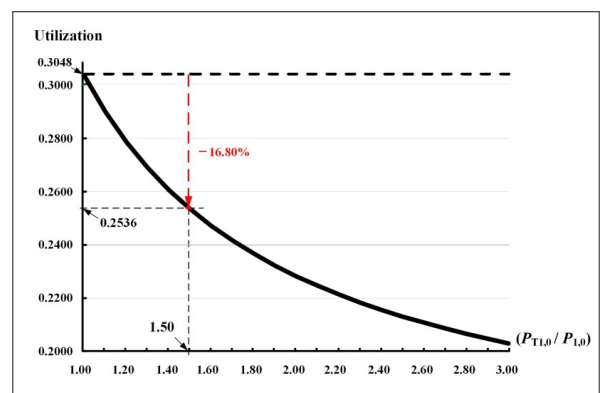

Fig. 12. The impact on utilization relating to $\left(P_{\mathrm{T} 1,0} / P_{1,0}\right)$

Fig.12 discloses the influence on utilization relating to the expedited ratio $\left(P_{\mathrm{T} 1,0} / P_{1,0}\right)$. At $\left(P_{\mathrm{T} 1,0} / P_{1,0}\right)=1.5$, the utilization drops to 0.2536 from 0.3048 , a $16.80 \%$ decline. Fig. 13 illustrates the collective effect of $\left(P_{\mathrm{T} 1,0} / P_{1,0}\right)$ and various mean $x_{i}$ on $E\left[T C U\left(T_{\mathrm{A}}^{*}, n^{*}\right)\right]$. As both $\left(P_{\mathrm{T} 1,0} / P_{1,0}\right)$ ratio and mean $x_{i}$ rise, $E\left[T C U\left(T_{\mathrm{A}}^{*}, n^{*}\right)\right]$ significantly surges. At $\left(P_{\mathrm{T} 1,0} / P_{1,0}\right)=1.5$, it reconfirms $E\left[T C U\left(T_{\mathrm{A}}^{*}, n^{*}\right)\right]=\$ 2,459,701$ (i.e., our example's optimal solution).

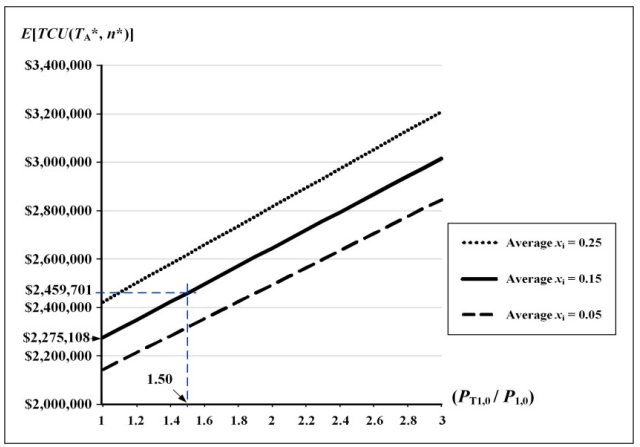

Fig. 13. The collective effect of $\left(P_{\mathrm{T} 1,0} / P_{1,0}\right)$ and various mean $x_{i}$ on $E\left[T C U\left(T_{\mathrm{A}}^{*}, n^{*}\right)\right]$

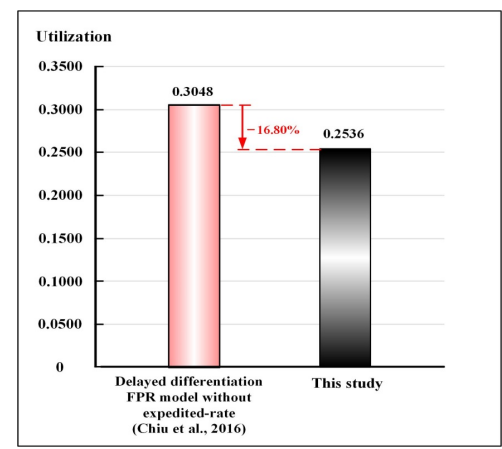

Fig. 14. Comparison of our study's utilization with a closely related existing work 
Fig. 14 compares this study's utilization with a closely related existing work (Chiu et al. (2016)). It indicates that by using the expedited rate for producing the common parts, our utilization drops a $16.80 \%$ compared to a similar model without expediting the common part's fabrication. However, we are paying a price of $8.11 \%$ increase in $E\left[T C U\left(T_{\mathrm{A}}^{*}, n^{*}\right)\right]($ i.e., rising from $\$ 2,275,108$ to $\$ 2,459,701$; see Fig. 13 ).

\subsection{The collective effects of critical system features on the problem}

The proposed model can provide production planners with the collective effects of critical system features on the studied problem. Figure 15 depicts the joint influences of the expedited-rate added output proportion $\alpha_{1,0}$ and mean scrap rate $x_{i}$ on $E\left[T C U\left(T_{\mathrm{A}}^{*}, n^{*}\right)\right]$. As both $\alpha_{1,0}$ and mean $x_{i}$ rise, $E\left[T C U\left(T_{\mathrm{A}}^{*}, n^{*}\right)\right]$ noticeably surges. It reveals the mean $x_{i}$ has more influence on $E\left[T C U\left(T_{\mathrm{A}}^{*}, n^{*}\right)\right]$ than that of $\alpha_{1,0}$.

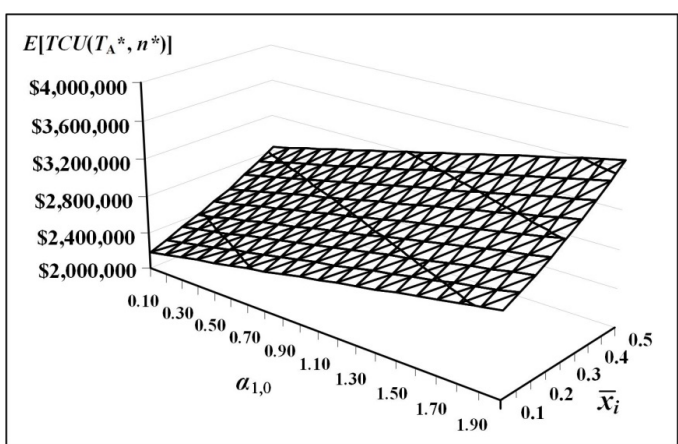

Fig. 15. The combined influences on $E\left[T C U\left(T_{\mathrm{A}}^{*}, n^{*}\right)\right]$ relating to $\alpha_{1,0}$ and mean $x_{i}$

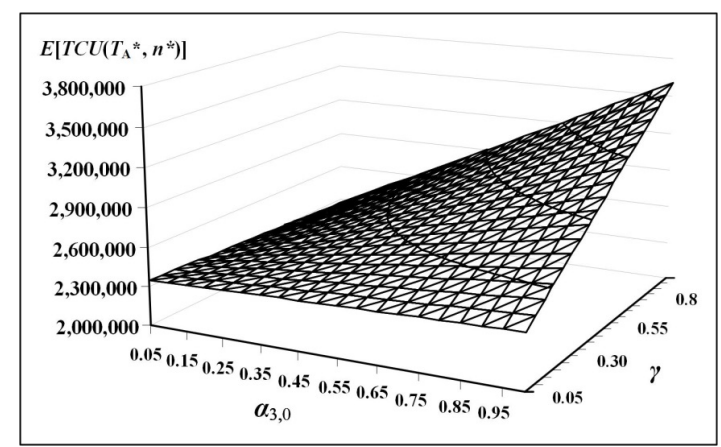

Fig. 16. The collective impact on $E\left[T C U\left(T_{\mathrm{A}}^{*}, n^{*}\right)\right]$ concerning $\alpha_{3,0}$ and $\gamma$

Fig. 16 reveals the joint impact of the expedited-rate added unit cost proportion $\alpha_{3,0}$ and $\gamma$ on $E\left[T C U\left(T_{\mathrm{A}}{ }^{*}, n^{*}\right)\right]$. It discloses $E\left[T C U\left(T_{\mathrm{A}}^{*}, n^{*}\right)\right]$ slightly changes as both $\alpha_{3,0}$ and $\gamma$ remain at the lower point, and $E\left[T C U\left(T_{\mathrm{A}}^{*}, n^{*}\right)\right]$ upsurges severely, as both $\alpha_{3,0}$ and $\gamma$ increase to the high end. Fig. 17 shows mutual effects of the expedited-rate added output proportion $\alpha_{1,0}$ and mean scrap rate $x_{i}$ on stage one's optimal uptime $t_{0} *$. As mean $x_{i}$ rises, $t_{0} *$ changes a little. In contrast, $t_{0}^{*}$ noticeably declines as $\alpha_{1,0}$ increases. Also, it reveals that the changing of the $n^{*}$ value has caused an irregular variation in $t_{0} *$.

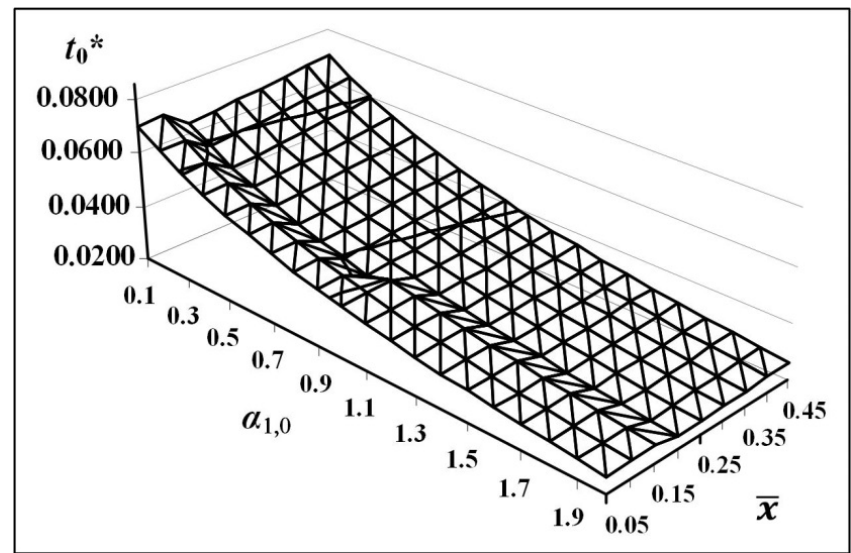

Fig. 17. The mutual effects on $t_{0} *$ regarding $\alpha_{1,0}$ and mean $x_{i}$

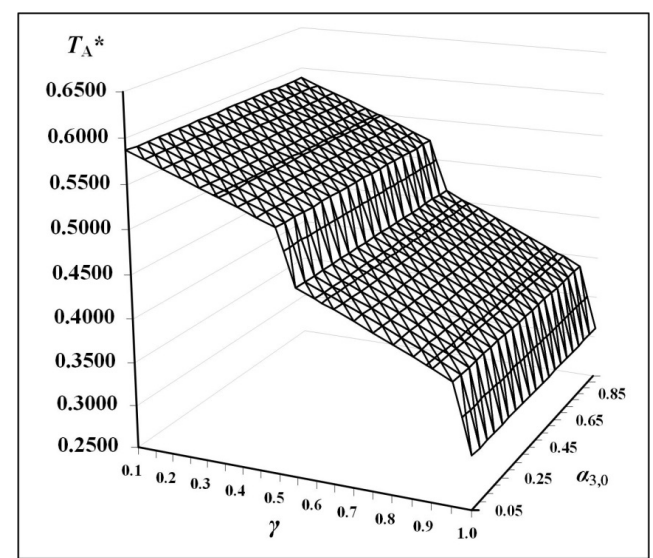

Fig. 18. The combined impact on $T_{\mathrm{A}}{ }^{*}$ relating to $\gamma$ and $\alpha_{3,0}$

Furthermore, Fig. 18 exposes the combined impact of $\gamma$ and $\alpha_{3,0}$ on the optimal replenishing cycle time $T_{\mathrm{A}}{ }^{*}$. As $\gamma$ rises, $T_{\mathrm{A}}{ }^{*}$ drastically decreases, and as $\alpha_{3,0}$ increases, $T_{\mathrm{A}} *$ insignificantly varies. It reveals that $\gamma$ has more impact on $T_{\mathrm{A}} *$ than $\alpha_{3,0}$. The rising $\gamma$ value has caused the $n^{*}$ value to change, and hence, $T_{\mathrm{A}} *$ has a sharp decline accordingly.

\section{Conclusions}

The present study utilizes mathematical modeling to develop a producer-retailer incorporated multi-item two-stage EPQ system with delayed differentiation, expedited-rate for producing common parts, random scrap, and multiple deliveries plan. Upon finding the overall system expenses function, Hessian matrix equations assist us in showing its convexity and determining the cost-minimized fabrication-delivery decision. A simulated example helps this study validate our research outcome's applicability and the proposed system's capabilities numerically. The critical contribution of the present study includes: (1) we propose a feasible/practical approach to enable the exploration of a producer-retailer incorporated multi- 
item delayed differentiation EPQ system with specific characteristics; (2) we further validate that our model can disclose different crucial system-related information to facilitate various critical decision-making for manufacturers to achieve their operational goals. A worthy investigation of future work is to examine the effect of incorporating the expedited rate for end products into stage two of the same problem.

\section{Appendix - A}

The following are detailed derivations of Eq. (26).

By substituting Eqs. (1) to (24) in $T C\left(T_{\mathrm{A}}, n\right)$ (i.e., Eq. (25)), employing the expected values $E\left[x_{0}\right]$ and $E\left[x_{i}\right]$ to cope with random scrap proportions, and computing $E\left[T C\left(T_{\mathrm{A}}, n\right)\right] / E\left[T_{\mathrm{A}}\right]$, we gain $E\left[T C U\left(T_{\mathrm{A}}, n\right)\right]$ as follows:

$$
\begin{aligned}
& E\left[\operatorname{TCU}\left(T_{A}, n\right)\right]=\frac{E\left[T C\left(T_{A}, n\right)\right]}{E\left[T_{A}\right]}=\frac{\left(1+\alpha_{3,0}\right) C_{0} \lambda_{0}}{1-E\left[x_{0}\right]}+\frac{\left(1+\alpha_{2,0}\right) K_{0}}{T_{A}} \\
& +\frac{C_{S, 0} E\left[x_{0}\right] \lambda_{0}}{1-E\left[x_{0}\right]}+h_{4,0}\left(\frac{E\left[x_{0}\right] \lambda_{0} T_{A}}{1-E\left[x_{0}\right]}\right)+h_{1,0} \sum_{i=1}^{L}\left(\frac{1}{2 P_{1, i}}\right) \frac{\lambda_{i}^{2} T_{A}}{\left(1-E\left[x_{i}\right]\right)^{2}} \\
& +h_{1,0}\left\{\begin{array}{l}
\left(\frac{1}{2}\right)\left(\frac{\lambda_{0}^{2} T_{A}}{\left(1-E\left[x_{0}\right]\right)^{2}}\right)\left[\frac{1}{\left(1+\alpha_{1,0}\right) P_{1,0}}\right] \\
+\sum_{i=1}^{L}\left\{-\left[\frac{\lambda_{i} T_{A}}{1-E\left[x_{i}\right]}\right]\left(\frac{1}{P_{1, i}}\right)\right\}\left[\sum_{j=1}^{i}\left(\frac{\lambda_{j}}{1-E\left[x_{j}\right]}\right)\right]+\left[\sum_{i=1}^{L}\left(\frac{\lambda_{i}}{1-E\left[x_{i}\right]}\right)\right] \cdot \sum_{i=1}^{L}\left[\frac{\lambda_{i} T_{A}}{1-E\left[x_{i}\right]}\right]\left(\frac{1}{P_{1, i}}\right)
\end{array}\right\} \\
& C_{i}\left(\frac{\lambda_{i}}{1-E\left[x_{i}\right]}\right)+\frac{K_{i}}{T_{A}}+C_{S, i} E\left[x_{i}\right]\left(\frac{\lambda_{i}}{1-E\left[x_{i}\right]}\right) \\
& +\sum_{i=1}^{L}\left\{+\frac{n K_{D, i}}{T_{A}}+C_{D, i} \lambda_{i}+\frac{h_{1, i} \lambda_{i}^{2} T_{A}}{2}\left[\frac{1}{\lambda_{i}}+\frac{E\left[x_{i}\right]}{\left(1-E\left[x_{i}\right]\right)^{2} P_{1, i}}\right]+h_{4, i}\left[\frac{E\left[x_{i}\right] \lambda_{i} T_{A}}{1-E\left[x_{i}\right]}\right]\right\} \\
& \left.+\frac{h_{3, i}}{2}\left[\frac{\lambda_{i}^{2} T_{A}}{1-E\left[x_{i}\right]}\right]\left(\frac{1}{P_{1, i}}\right)+\frac{\left(h_{3, i}-h_{1, i}\right) \lambda_{i}^{2} T_{A}}{2 n}\left[\frac{1}{\lambda_{i}}-\frac{1}{P_{1, i}\left(1-E\left[x_{i}\right]\right)}\right]\right)
\end{aligned}
$$

Let $E_{0 i}, E_{1 i}, E_{00}, E_{10}$, and $E_{0 j}$ be the following:

$$
\begin{aligned}
& E_{0 i}=\frac{1}{\left(1-E\left[x_{i}\right]\right)} \text { and } E_{1 i}=\frac{E\left[x_{i}\right]}{\left(1-E\left[x_{i}\right]\right)} \text { for } i=1,2, \ldots, L \\
& E_{00}=\frac{1}{\left(1-E\left[x_{0}\right]\right)} ; E_{10}=\frac{E\left[x_{0}\right]}{\left(1-E\left[x_{0}\right]\right)} ; E_{0 j}=\frac{1}{\left(1-E\left[x_{j}\right]\right)} \text { for } j=1,2, \ldots, i .
\end{aligned}
$$

By substituting Eq. (A-2) in Eq. (A-1), we have the following:

$$
\begin{aligned}
& E\left[\operatorname{TCU}\left(T_{A}, n\right)\right]=\frac{\left(1+\alpha_{2,0}\right) K_{0}}{T_{A}}+\left(1+\alpha_{3,0}\right) C_{0} \lambda_{0} E_{00} \\
& +C_{S, 0} E_{10} \lambda_{0}+h_{4,0} \lambda_{0} E_{10} T_{A}+h_{1,0} \sum_{i=1}^{L}\left(\frac{1}{2 P_{1, i}}\right) \lambda_{i}^{2}\left(E_{0 i}\right)^{2} T_{A} \\
& +h_{1,0}\left\{\left(\frac{1}{2}\right) \lambda_{0}^{2}\left(E_{00}\right)^{2} T_{A}\left[\frac{1}{\left(1+\alpha_{1,0}\right) P_{1,0}}\right]\right. \\
& +h_{1,0}\left\{+\sum_{i=1}^{L}\left[-\lambda_{i} E_{0 i} T_{A}\left(\frac{1}{P_{1, i}}\right)\right]\left[\sum_{j=1}^{i}\left(\lambda_{j} E_{0 j}\right)\right]+\left[\sum_{i=1}^{L}\left(\lambda_{i} E_{0 i}\right)\right] \cdot \sum_{i=1}^{L}\left[\lambda_{i} E_{0 i} T_{A}\right]\left(\frac{1}{P_{1, i}}\right)\right\} \\
& +\sum_{i=1}^{L}\left\{\begin{array}{l}
C_{i} \lambda_{i} E_{0 i}+\frac{K_{i}}{T_{A}}+C_{S, i}\left(\lambda_{i} E_{1 i}\right)+\frac{n K_{D, i}}{T_{A}}+C_{D, i} \lambda_{i}+\frac{h_{1, i} \lambda_{i}^{2} T_{A}}{2}\left[\frac{1}{\lambda_{i}}+\frac{E_{0 i} E_{1 i}}{P_{1, i}}\right]+h_{4, i} \lambda_{i} E_{1 i} T_{A} \\
+\frac{h_{3, i}}{2}\left(\frac{\lambda_{i}^{2}}{P_{1, i}}\right) E_{0 i} T_{A}+\frac{\left(h_{3, i}-h_{1, i}\right) \lambda_{i}^{2} T_{A}}{2 n}\left[\frac{1}{\lambda_{i}}-\frac{E_{0 i}}{P_{1, i}}\right]
\end{array}\right\}
\end{aligned}
$$

Let $E_{0 P}, E_{2 i}$, and $E_{i P}$ represent the following:

$$
\begin{aligned}
& E_{0 P}=\left[\frac{1}{\left(1+\alpha_{1,0}\right) P_{1,0}}\right] ; \\
& E_{2 i}=\left[\frac{1}{\lambda_{i}}+\frac{E_{0 i} E_{1 i}}{P_{1, i}}\right] ; E_{i P}=\left[\frac{1}{\lambda_{i}}-\frac{E_{0 i}}{P_{1, i}}\right] \text { for } i=1,2, \ldots, L .
\end{aligned}
$$


By substituting Eq. (A-4) in Eq. (A-3), Eq. (26) is gained as follows:

$$
\begin{aligned}
E[ & \left.T C U\left(T_{A}, n\right)\right]=\left(1+\alpha_{3,0}\right) C_{0} \lambda_{0} E_{00}+\frac{\left(1+\alpha_{2,0}\right) K_{0}}{T_{A}} \\
& +C_{S, 0} E_{10} \lambda_{0}+h_{4,0} \lambda_{0} E_{10} T_{A}+h_{1,0} \sum_{i=1}^{L}\left(\frac{1}{2 P_{1, i}}\right) \lambda_{i}^{2}\left(E_{0 i}\right)^{2} T_{A} \\
& +h_{1,0}\left\{\begin{array}{l}
\left.\left(\frac{1}{2}\right) \lambda_{0}^{2}\left(E_{00}\right)^{2} T_{A} E_{0 P}+\sum_{i=1}^{L}\left(\frac{-\lambda_{i} E_{0 i} T_{A}}{P_{1, i}}\right)\left[\sum_{j=1}^{i}\left(\lambda_{j} E_{0 j}\right)\right]+\left[\sum_{i=1}^{L}\left(\lambda_{i} E_{0 i}\right)\right] \cdot \sum_{i=1}^{L}\left(\frac{\lambda_{i} E_{0 i} T_{A}}{P_{1, i}}\right)\right\} \\
+
\end{array}\right. \\
& +\sum_{i=1}^{L}\left\{\begin{array}{l}
C_{i} \lambda_{i} E_{0 i}+\frac{K_{i}}{T_{A}}+C_{S, i}\left(\lambda_{i} E_{1 i}\right)+\frac{n K_{D, i}}{T_{A}}+C_{D, i} \lambda_{i}+\frac{h_{1, i} \lambda_{i}^{2} T_{A} E_{2 i}}{2}+h_{4, i} \lambda_{i} E_{1 i} T_{A} \\
+\frac{h_{3, i}}{2}\left(\frac{E_{0 i}}{P_{1, i}}\right)^{2} \lambda_{i}^{2} T_{A}+\frac{\left(h_{3, i}-h_{1, i}\right) \lambda_{i}^{2} T_{A} E_{i P}}{2 n}
\end{array}\right\}
\end{aligned}
$$

\begin{tabular}{|c|c|c|c|c|c|c|c|c|c|c|c|}
\hline Product $i$ & $C_{\mathrm{D}, i}$ & $x_{i}$ & $C_{\mathrm{S}, i}$ & $K_{D, i}$ & $P_{1, i}$ & $K_{i}$ & $\lambda_{i}$ & $C_{i}$ & $h_{1, i}$ & $h_{4, i}$ & $h_{3, i}$ \\
\hline 1 & $\$ 0.1$ & $5 \%$ & $\$ 20$ & $\$ 1800$ & 58000 & $\$ 17000$ & 3000 & $\$ 80$ & $\$ 16$ & $\$ 16$ & $\$ 70$ \\
\hline 2 & $\$ 0.2$ & $10 \%$ & $\$ 25$ & $\$ 1900$ & 59000 & $\$ 17500$ & 3200 & $\$ 90$ & $\$ 18$ & $\$ 18$ & $\$ 75$ \\
\hline 3 & $\$ 0.3$ & $15 \%$ & $\$ 30$ & $\$ 2000$ & 60000 & $\$ 18000$ & 3400 & $\$ 100$ & $\$ 20$ & $\$ 20$ & $\$ 80$ \\
\hline 4 & $\$ 0.4$ & $20 \%$ & $\$ 35$ & $\$ 2100$ & 61000 & $\$ 18500$ & 3600 & $\$ 110$ & $\$ 22$ & $\$ 22$ & $\$ 85$ \\
\hline 5 & $\$ 0.5$ & $25 \%$ & $\$ 40$ & $\$ 2200$ & 62000 & $\$ 19000$ & 3800 & $\$ 120$ & $\$ 24$ & $\$ 24$ & $\$ 90$ \\
\hline
\end{tabular}

\section{Appendix - B}

\section{Table B-1}

The assumed parameters' values for the corresponding one-stage system

\section{References}

Aouam, T., \& Kumar, K. (2019). On the effect of overtime and subcontracting on supply chain safety stocks. Omega, 89, 120

Arslan, H., Ayhan, H., \& Olsen, T.L. (2001). Analytic models for when and how to expedite in make-to-order systems. IIE Transaction, 33(11), 1019-1029

Ayed, S., Sofiene, D., \& Nidhal, R. (2011). Joint optimisation of maintenance and production policies considering random demand and variable production rate. International Journal of Production Research, 50(23), 6870-6885.

Cavusoglu, H., Cavusoglu, H., \& Raghunathan, S. (2012). Value of and interaction between production postponement and information sharing strategies for supply chain firms. Production and Operations Management, 21(3), 470-488.

Chiu, Y-S.P., Hsieh, Y-T., Kuo, J-S., \& Chiu, S.W. (2016). A delayed differentiation multi-product FPR model with scrap and a multi-delivery policy - I: Using single-machine production scheme. International Journal for Engineering Modelling, 29(1-4), 37-52.

Chiu, Y-S.P., Chiu, V., Lin, H-D., Chiu, T. (2019). An EMQ-based system considering machine malfunction, allowable backlogging level, repairable items, and discontinuous issuing policy. Journal of Engineering Research, 7(4), $276-298$.

Chiu, S.W., You, L-W., Yeh, T-M., Chiu, T. (2020a). The collective influence of component commonality, adjustable-rate, postponement, and rework on multi-item manufacturing decision. Mathematics. 8(9), Art. No. 1570, 1-18

Chiu, Y-S.P., Chiu, V., Yeh, T-M., Wu, H-Y. (2020b). Incorporating outsourcing strategy and quality assurance into a multiproduct manufacturer-retailer coordination replenishing decision. Mathematics, 8(12), Art. No. 02212, 1-19.

Chiu, Y-S.P., Wu, C-S., Wu, H.Y., Chiu, S.W. (2021). Studying the effect of stochastic breakdowns, overtime, and rework on inventory replenishment decision. Alexandria Engineering Journal, 60(1), 1627-1637

Farsijani, H., Nikabadi, M.S., \& Ayough, A. (2012). A simulated annealing approach to optimize multi-products EPQ model with discrete delivery orders, imperfect production processes and service level constraint. World Applied Sciences Journal, $16(8), 1142-1157$.

Gera, A.E. (2021). The reliability of a system involving change points. International Journal of Mathematical, Engineering and Management Sciences, 6(1), 296-308.

Gilotra, M., Pareek, S., Mittal, M., \& Dhaka, V. (2020). Effect of carbon emission and human errors on a two-echelon supply chain under permissible delay in payments. International Journal of Mathematical, Engineering and Management Sciences, 5(2), 225-236.

Gupta, D., \& Benjaafar, S. (2004). Make-to-order, make-to-stock, or delay product differentiation? A common framework for modeling and analysis, IIE Transactions, 36(6), 529-546.

Jabbarzadeh, A., Haughton, M., \& Pourmehdi, F. (2019). A robust optimization model for efficient and green supply chain planning with postponement strategy. International Journal of Production Economics, 214, 266-283. 
Jeunet, J., \& Bou Orm, M. (2020). Optimizing temporary work and overtime in the time cost quality trade-off Problem. European Journal of Operational Research, 284, 743-761

Kauppila, O., Valikangas, K., \& Majava, J. (2020). Improving supply chain transparency between a manufacturer and suppliers: A triadic case study. Management and Production Engineering Review, 11(3), 84-91.

Köksal, G., Taşeli, A., Dolgun, L.E., \& Batmaz, I. (2013). The effect of inspection error on quality and producer losses: The case of nominal-the-best type quality characteristic and rework. European Journal of Industrial Engineering, 7(4), 497528.

Larkin, E.V., \&Privalov, A.N. (2019). Engineering method of fault-tolerant system simulations. Journal of Applied Engineering Science, 17(3), 295-303.

Lesmono, D., Limansyah, T., \& Loedy, N. (2020). A joint return policy for a multi-item perishable inventory model with deterministic demands, return and all-units discount. International Journal of Mathematical, Engineering and Management Sciences, 5(3), 416-431.

Lin, H-D., Chen, Y-R., Chiu, V., \& Chiu, Y-S.P. (2019). A decision model for a quality-assured EPQ-based intra-supply chain system considering overtime option. Journal of Applied Engineering Science, 17(3), 362-371.

López-Ruíz, S., \& Carmona-Benítez, R.B. (2019). The design of a liquefied natural gas (LNG) distribution network of a company operating in Mexico. Journal of Applied Research and Technology, 17(4), 213-249.

Marchi, B., Zanoni, S., Jaber, M.Y. (2019). Economic production quantity model with learning in production, quality, reliability and energy efficiency. Computers \& Industrial Engineering, 129, 502-511.

Mokao, R. (2020). Multi criteria decision making model for producing multiple products at the same time. Management and Production Engineering Review, 11(3), 92-105.

Nahmias, S. (2009). Production \& Operations Analysis. McGraw-Hill Inc. New York.

Ortiz-Servin, J.J., Castillo, A., \& Talavera, F. (2019). A new methodology to optimize operation cycles in a bwr using heuristic techniques. Journal of Applied Research and Technology, 17(3), 155-162.

Palyanitsina, A., \& Sukhikh, A. (2020). Peculiarities of assessing the reservoir propties of clayish reservoirs depending on the water of reservoir pressure maintenance system properties. Journal of Applied Engineering Science, 18(1), 10-14.

Pawar, P.J., \& Nandurkar, K.N. (2018). Optimization of single supplier multi buyer multi product supply chain system. Procedia Manufacturing, 26, 21-28.

Pramono, S.N.W., Ulkhaq, M.M., Rachmadina, D.P., Trianto, R., Rachmadani, A.P., Wijayanti, W.R., \& Dewi, W.R. (2018). The use of quality management techniques: The application of the new seven tools. International Journal of Applied Science and Engineering, 15(2), 105-112.

Rardin R.L. (1998). Optimization in Operations Research. Prentice-Hall; New Jersey, USA.

Rout, C., Chakraborty, D., \& Goswami, A. (2020). An EPQ model for deteriorating items with imperfect production, two Types of inspection errors and rework under complete backordering. International Game Theory Review, 22(2), Art. No. 2040011.

Ruidas, S. Seikh, M.R., \& Nayak, P.K. (2020). An EPQ model with stock and selling price dependent demand and variable production rate in interval environment. International Journal of Systems Assurance Engineering and Management, 11(2), 385-399.

Taft, E.W. (1918). The most economical production lot. Iron Age, 101, 1410-1412.

Tantiwattanakul, P., \& Dumrongsiri, A. (2019). Supply chain coordination using wholesale prices with multiple products, multiple periods, and multiple retailers: Bi-level optimization approach. Computers \& Industrial Engineering, 131, 391407.

Tian, Q., Guo, W. (2019). Reconfiguration of manufacturing supply chains considering outsourcing decisions and supply chain risks. Journal of Manufacturing Systems, 52(Part B), 217-226

Trisna, T., Marimin, M., Arkeman, Y., \& Sunarti, T.C. (2020). Fuzzy multi-objective optimization for wheat flour supply chain considering raw material substitution. International Journal of Industrial Engineering and Management, 11(3), 180191. 
(C) 2021 by the authors; licensee Growing Science, Canada. This is an open access article distributed under the terms and conditions of the Creative Commons Attribution (CCBY) license (http://creativecommons.org/licenses/by/4.0/). 